\title{
Proline accumulation is associated with inhibition of rice seedling root growth caused by $\mathrm{NaCl}$
}

\author{
Chuan Chi Lin, Ching Huei Kao* \\ Department of Agronomy, National Taiwan University, Taipei, Taiwan, Republic of China
}

Received 18 May 1995; revision received 12 December 1995; accepted 18 December 1995

\begin{abstract}
The effects of $\mathrm{NaCl}$ on changes in the proline level in roots and root growth of rice seedlings were investigated. $\mathrm{NaCl}$ was effective in inhibiting root growth and in increasing proline accumulation in roots. Mannitol was also effective in inhibiting root growth, but proline accumulation was observed only at the concentration iso-osmotic with $150 \mathrm{mM}$ $\mathrm{NaCl}$. Accumulation of proline in roots preceded inhibition of root growth caused by $\mathrm{NaCl}$. The inhibition of root growth and accumulation of proline in roots by $\mathrm{NaCl}$ are reversible. Exogenous L-proline and gabaculine, which were found to enhance in an accumulation of proline in roots, inhibited root growth of rice seedlings. The relationship between growth inhibition of roots caused by $\mathrm{NaCl}$ and changes in the proline level in roots is discussed.
\end{abstract}

Keywords: Gabaculine; NaCl; Oryza sativa L.; Proline; Root growth

\section{Introduction}

Proline accumulation in plant cells exposed to salt or water stress is a widespread phenomenon [1,2]. Proline is believed to protect plant tissues against stress by acting as an $\mathrm{N}$-storage compound, osmo-solute and hydrophobic protectant for enzymes and cellular structures [3]. However, its role in imparting resistance to salt stress continues to be controversial. Some workers consider enhanced proline levels simply as a stress effect, rather than a cause of stress tolerance [4-6]. There are reports that proline accumulation is correlated with growth inhibition induced by $\mathrm{NaCl}[7,8]$. The

\footnotetext{
* Corresponding author.
}

role of proline accumulation in salinity stress therefore needs to be critically examined. In this paper, we investigate the role of proline in the control of $\mathrm{NaCl}$-inhibited root growth of rice seedlings.

\section{Materials and methods}

Rice (Oryza sativa L., cv. Taichung Native 1) seeds were sterilized with $2.5 \%$ sodium hypochlorite for $15 \mathrm{~min}$ and washed extensively with distilled water. These seeds were then germinated in Petri dishes $(20-\mathrm{cm})$ containing distilled water at $37^{\circ} \mathrm{C}$ under dark conditions. After 1-day incubation, uniformly germinated seeds were selected and transferred to a Petri dish $(9.0-\mathrm{cm})$ containing 2 
sheets of Whatman No. 1 filter paper moistened with $10 \mathrm{ml}$ distilled water or test solution. All test compounds were dissolved in distilled water. Their pHs are similar to that of distilled water, which is 5.5. Each Petri dish contained 20 germinated seeds. Each treatment was replicated 4 times. The germinated seeds were allowed to grow at $27^{\circ} \mathrm{C}$ in darkness and an additional $3 \mathrm{ml}$ distilled water or test solutions was added to each Petri dish on day 3 of the growth.

Proline was extracted and its concentration determined by the method of Bates et al. [9]. Roots were homogenized with $3 \%$ sulfosalicylic acid and the homogenate was centrifuged. The supernatant was treated with acetic acid and acid ninhydrin, boiled for $1 \mathrm{~h}$ and then absorbance at $520 \mathrm{~nm}$ was determined. Levels of proline are expressed as $\mu \mathrm{mol} / \mathrm{g}$ dry weight.

For all measurements, each treatment was repeated 4 times. All experiments described here were repeated 3 times. Similar results and identical trends obtained each time. The data reported here are from a single experiment.

\section{Results}

Fig. 1 shows the effect of $\mathrm{NaCl}$ on the growth of rice seedlings. $\mathrm{NaCl}$ significantly reduced growth of shoots and roots, as judged by fresh weight and dry weight, of rice seedlings. Increasing concentrations of $\mathrm{NaCl}$ from 50 to $150 \mathrm{mM}$ progressively decreased root and shoot growth. Similar findings were recently reported when seedling growth was measured in terms of root and shoot length [10]. These results are in general agreement with those reported by Flowers and Yeo [11].

The effects of $\mathrm{NaCl}$ on proline levels in shoots and roots of rice seedlings are shown in Fig. 2. Increasing concentrations of $\mathrm{NaCl}$ from 50 to 150 $\mathrm{mM}$ progressively increased proline levels in roots. However, proline accumulation in shoots was observed only when seedlings were treated at high concentration $(150 \mathrm{mM})$ of $\mathrm{NaCl}$. Clearly, the reduction of root growth, but not shoot growth, is closely associated with the accumulation of proline in roots.

Mannitol inhibited root growth, but proline ac-

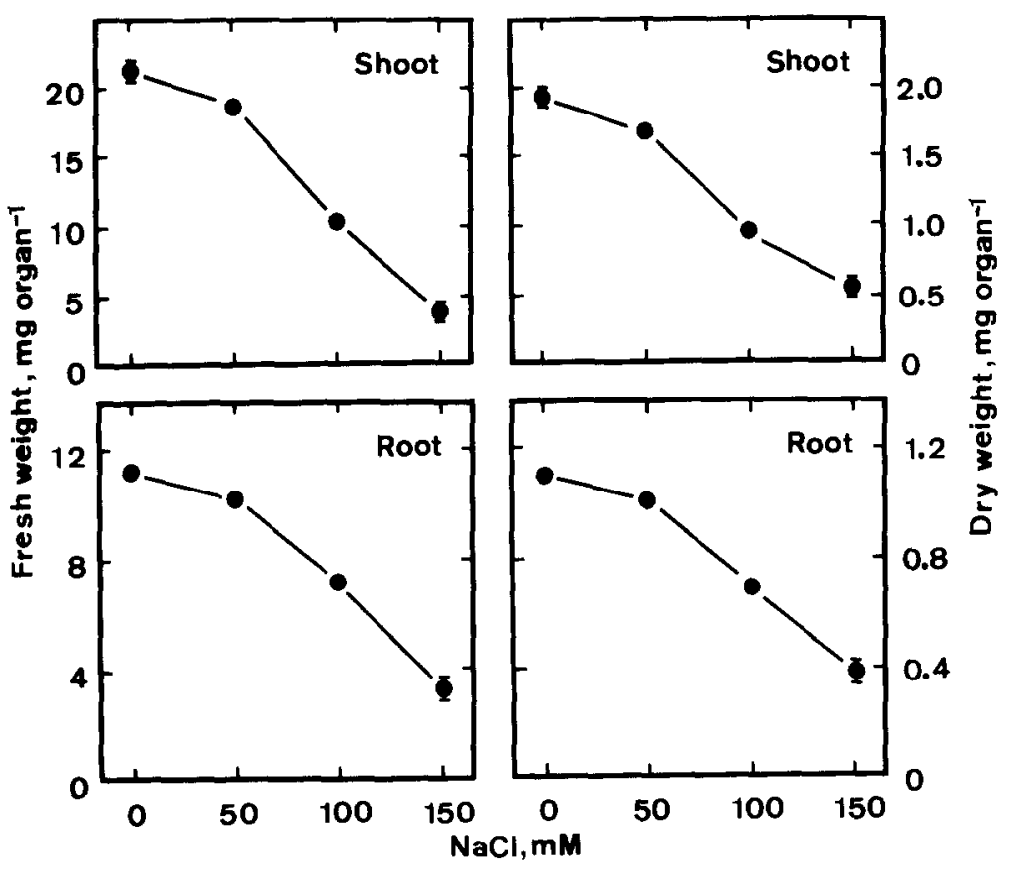

Fig. 1. Effects of $\mathrm{NaCl}$ on seedling growth of rice. Seedling growth was measured after 5 days of treatment. Vertical bars represent standard errors. Only those standard errors larger than symbol size are shown. 


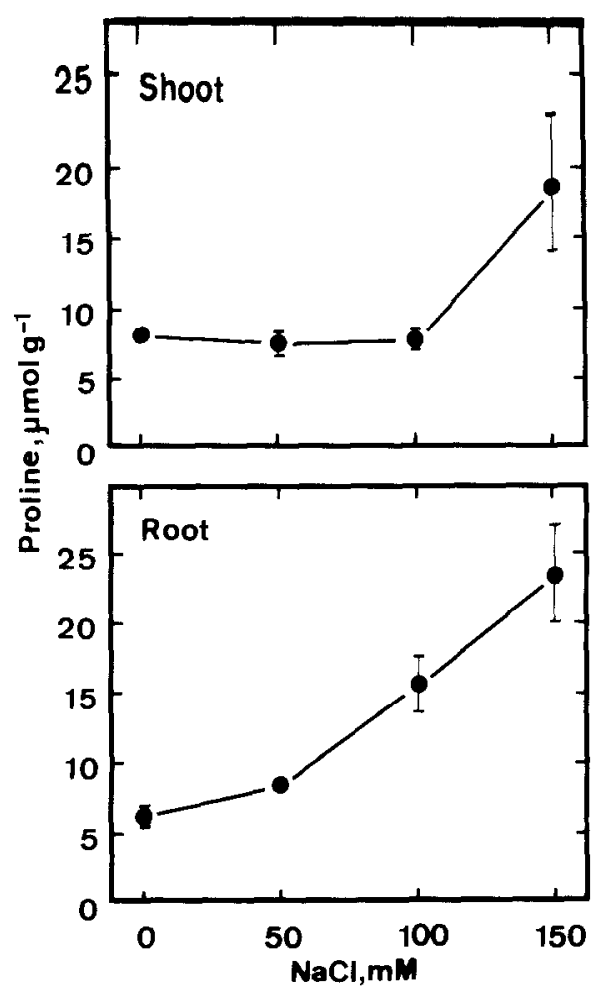

Fig. 2. Effects of $\mathrm{NaCl}$ on proline levels in shoots and roots of rice seedlings. Proline level was determined after 5 days of treatment. Vertical bars represent standard errors. Only those standard errors larger than symbol size are shown.

cumulation was observed only at a concentration iso-osmotic with $150 \mathrm{mM} \mathrm{NaCl}$ (Fig. 3). Mannitol treatment also inhibited shoot growth and resulted in an accumulation of proline. All these results suggest that proline accumulation in $\mathrm{NaCl}$-treated roots and shoots is associated with the ionic rather than the osmotic component of $\mathrm{NaCl}$ stress.

If proline accumulation is important in regulating growth inhibition of roots but not shoots of rice seedlings caused by $\mathrm{NaCl}$, then exogenous application of proline is expected to inhibit root growth but not shoot growth of rice seedlings. As indicated in Fig. 4, exogenous L-proline treatment resulted in an inhibition of root growth and an increase in proline level in roots. However, addjtion of L-proline did not affect shoot growth (Fig. 4). The effect of L-proline on root growth is unlikely to be due to microorganisms, since inhibition of root growth was also obtained when Lproline was added together with chloramphenicol
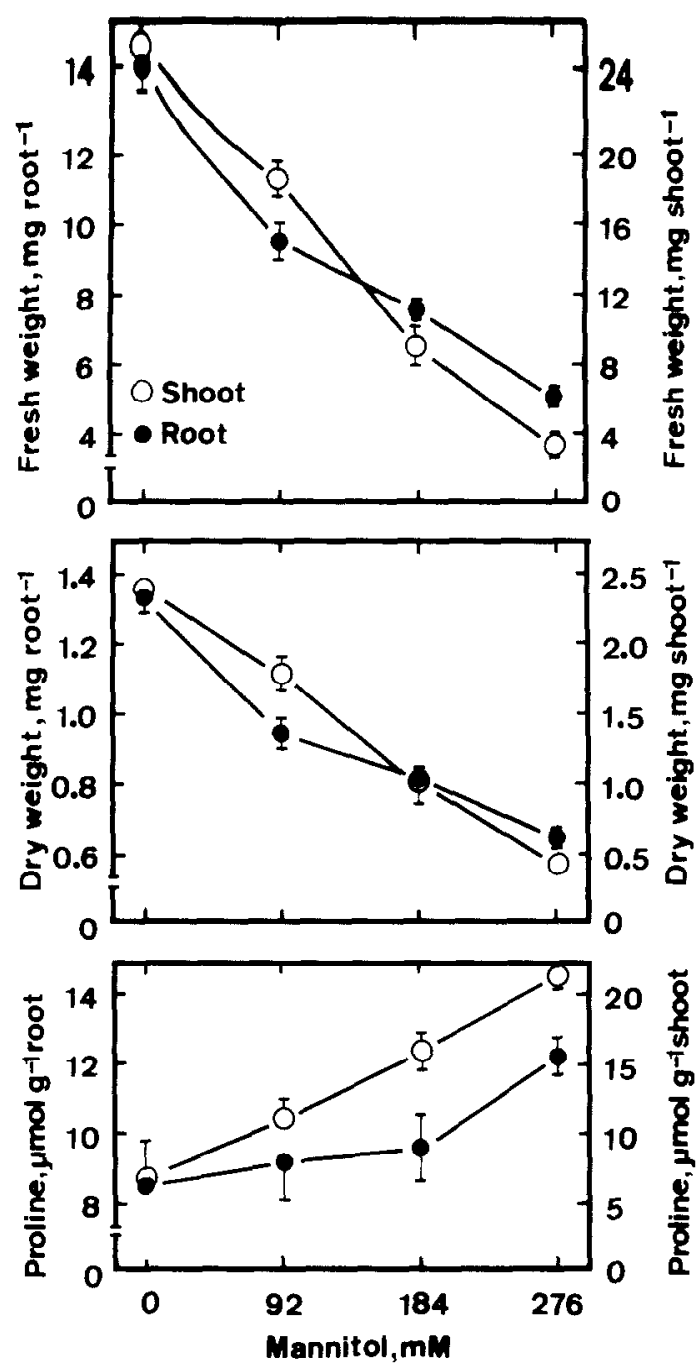

Fig. 3. Effects of mannitol on seedling growth and proline level in rice seedlings. Mannitol concentrations of $92,184,276 \mathrm{mM}$ were iso-osmotic with 50,100 and $150 \mathrm{mM}$, respectively. Seedling growth and proline level were measured after 5 days of treatment. Vertical bars represent standard errors.

$(0.25 \mathrm{mg} / \mathrm{l})$ to prevent bacterial growth. Chloramphenicol itself had no effect on root growth. In a recent work, we demonstrated that L-proline enhanced $\mathrm{NaCl}$-induced inhibition of root growth, but reversed the inhibitory effect of $\mathrm{NaCl}$ on shoot growth of rice seedlings [12]. It seems that proline may play different roles in regulating shoot and root growth of rice seedlings under $\mathrm{NaCl}$ conditions. 


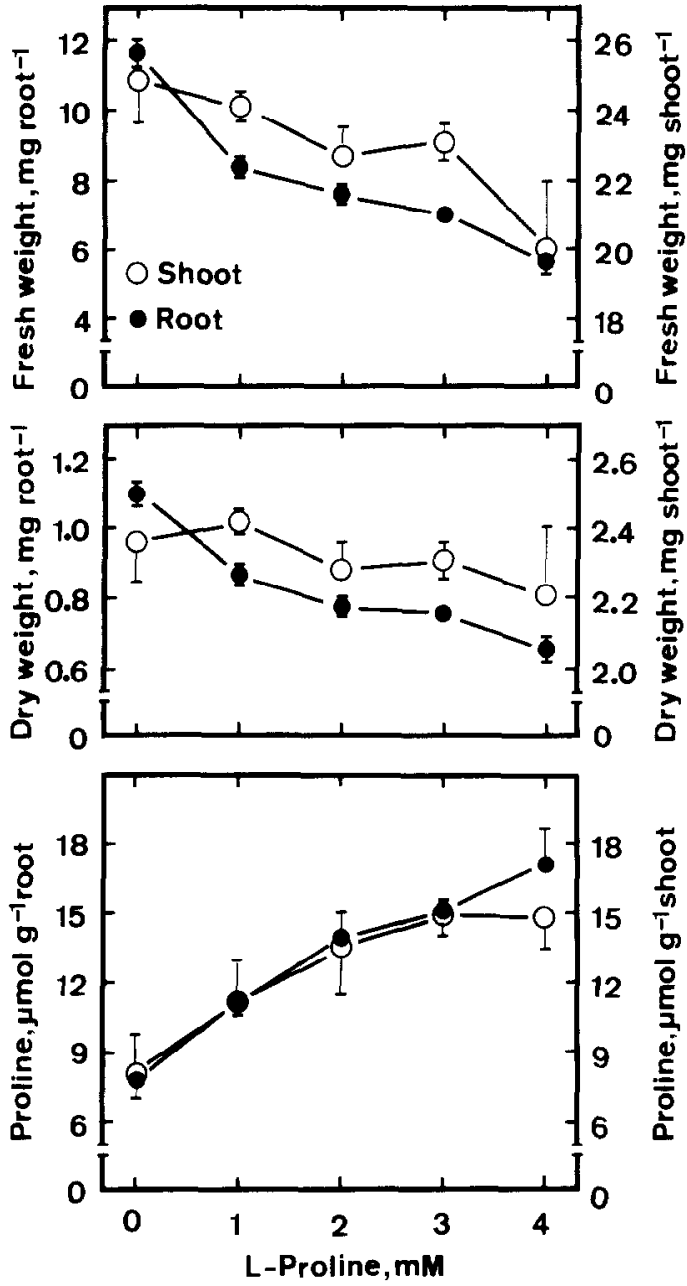

Fig. 4. Effects of L-proline on seedling growth and proline level in rice seedlings. Seedling growth and proline level were measured after 5 days of treatment. Vertical bars represent standard errors. Only those standard errors larger than symbol size are shown.

Kandpal and Rao [13] have proposed that ornithine aminotransferase may be a potential point of control of proline synthesis in plants subjected to stress. Gabaculine is known to inhibit ornithine aminotransferase [14] and has been shown to increase proline accumulation in radish cotyledons [15]. To characterize further the role of proline accumulation in regulating root growth reduction of rice seedlings under $\mathrm{NaCl}$ stress, rice seedlings were grown in the presence of various concentrations of gabaculine. As indicated in Fig. 5, gabaculine increased the proline level in roots and
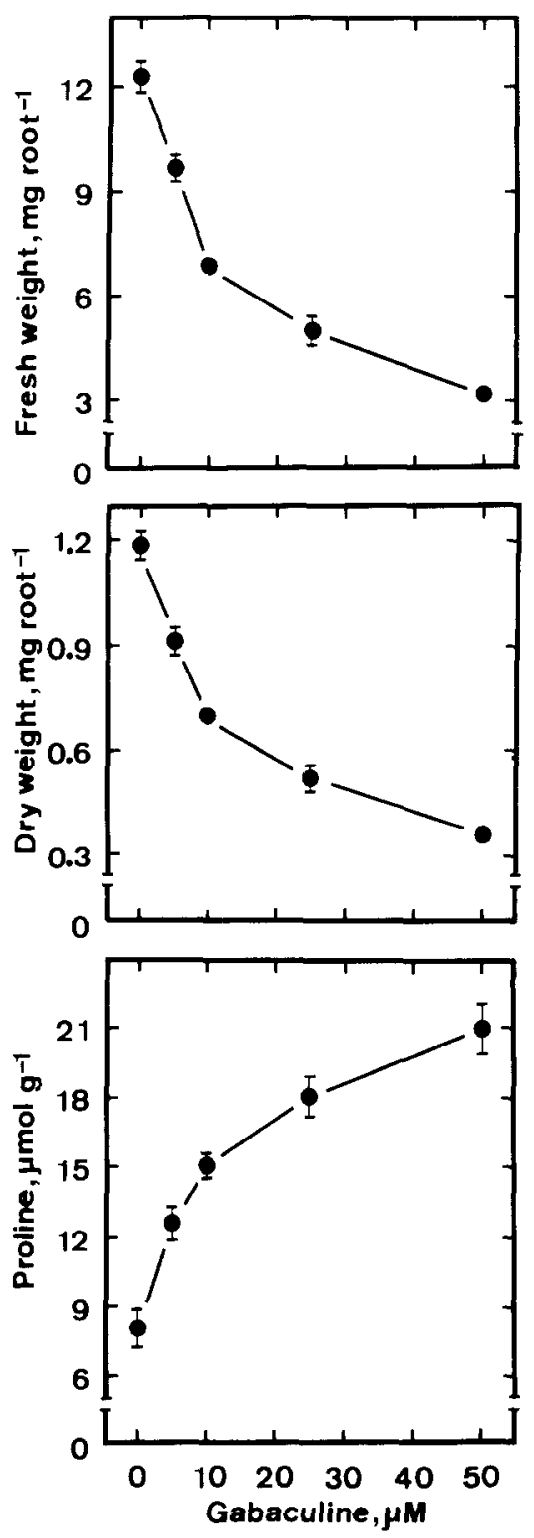

Fig. 5. Effects of gabaculine on root growth and proline level in roots of rice seedlings. Root growth and proline level were measured after 5 days of treatment. Vertical bars represent standard errors. Only those standard errors larger than symbol size are shown.

inhibited root growth. From the shape of the curves, it is apparent that the proline level is closely linked with root growth reduction.

If rice seedlings maintained for 2 days on $\mathrm{NaCl}$ 
or gabaculine are transferred to distilled water, they then resume root growth (Figs. 6 and 7). Root growth was only slightly restored if seedlings remained in $\mathrm{NaCl}$ or gabaculine (Figs. 6 and 7). Figs. 6 and 7 also show that the proline level in roots of seedlings remaining in $\mathrm{NaCl}$ or gabaculine
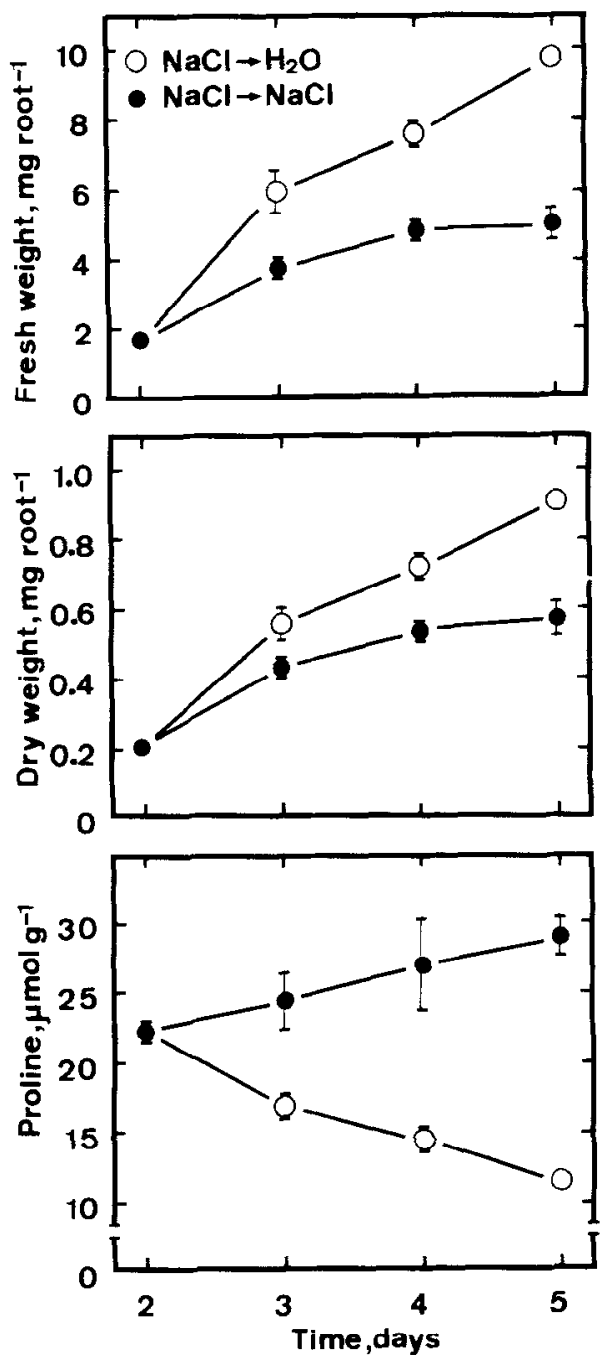

Fig. 6. Changes in growth of and proline level in roots of $\mathrm{NaCl}$ treated rice seedlings grown in the presence or absence of $\mathrm{NaCl}$ (150 mM). Rice seeds were germinated for 2 days in $\mathrm{NaCl}$ (150 $\mathrm{mM})$ and then seedlings were transferred to distilled water $(O)$ and $\mathrm{NaCl}(\Theta)$, respectively. Vertical bars represent standard errors. Only those standard errors larger than symbol size are shown.
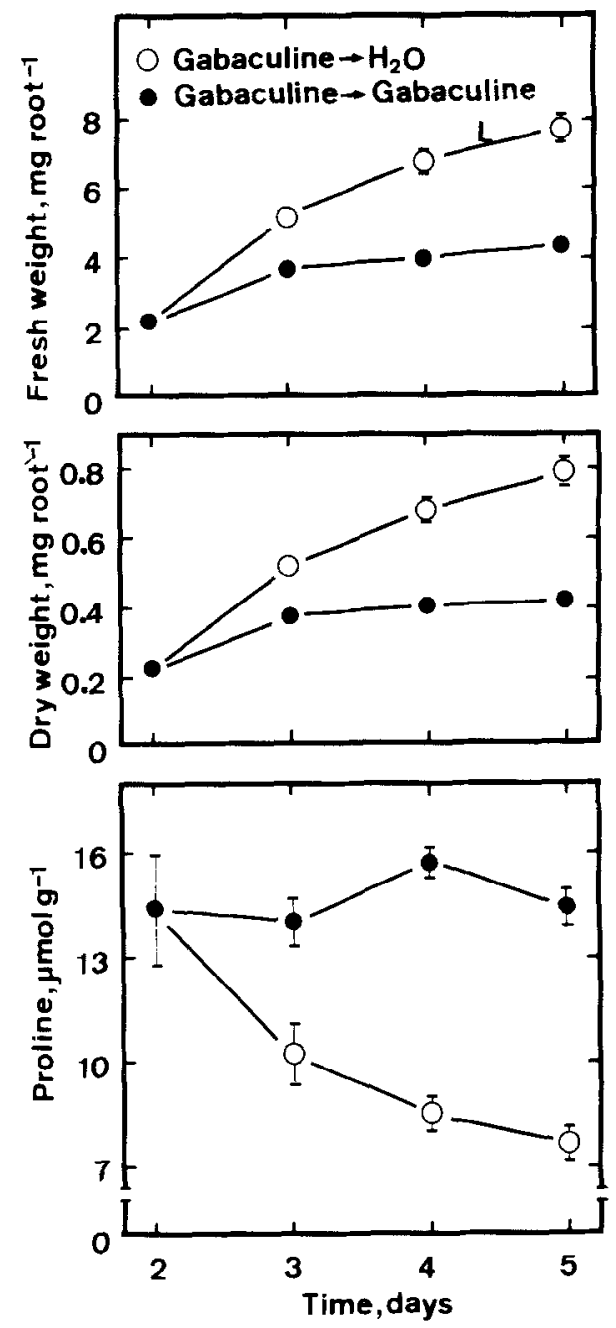

Fig. 7. Changes in growth of and proline level in roots of gabaculine-treated rice seedlings grown in the presence or absence of gabaculine $(25 \mu \mathrm{M})$. Rice seeds were germinated for 2 days in gabaculine $(25 \mu \mathrm{M})$ and then seedlings were transferred to distilled water $(O)$ and gabaculine $(O)$, respectively. Vertical bars represent standard errors. Only those standard errors larger than symbol size are shown.

medium is higher than that of seedlings transferred to distilled water.

To test the causal relationship between proline accumulation and root growth reduction caused by $\mathrm{NaCl}, 2$-day old seedlings were transferred to distilled water and $\mathrm{NaCl}$ medium for 4, 8, 12 and $16 \mathrm{~h}$, respectively. Changes in proline levels in roots and root growth were then monitored. As in- 

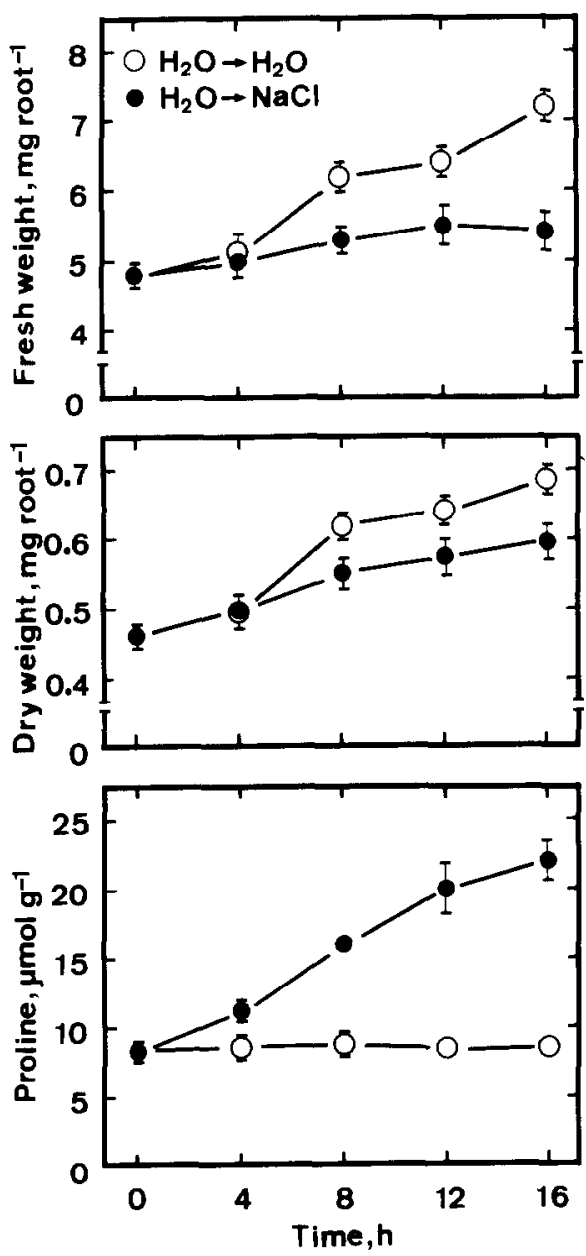

Fig. 8. Changes in growth of and proline level in roots of $\mathrm{NaCl}$ treated rice seedlings grown in the presence or absence of $\mathrm{NaCl}$ $(150 \mathrm{mM})$. Rice seeds were germinated for 2 days in distilled water and then seedlings were transferred to distilled water $(O)$ and $\mathrm{NaCl}(\Theta)$, respectively. Vertical bars represent standard errors. Only those standard errors larger than symbol size are shown.

dicated in Fig. 8, proline accumulation was observed at $4 \mathrm{~h}$ after $\mathrm{NaCl}$ treatment, whereas root growth was observed to be inhibited at $8 \mathrm{~h}$.

\section{Discussion}

Rice is a salt-sensitive species and accumulates sodium ion at only moderate external salinities [16]. Among different parameters responding to
$\mathrm{NaCl}$-stress in rice, the most significant one is rapid accumulation of proline $[17,18]$. The present investigation shows that the proline level in roots is closely associated with the $\mathrm{NaCl}$ concentration applied, whereas proline accumulation in shoots was observed only at high concentration of $\mathrm{NaCl}$ $(150 \mathrm{mM})$. We also indicate that proline accumulation in $\mathrm{NaCl}$-treated roots is associated with the ionic rather than the osmotic component of $\mathrm{NaCl}$ stress.

The present investigation indicates that proline accumulation participates in the regulation of root growth of rice seedlings under $\mathrm{NaCl}$ conditions. This conclusion was based on the observations that (a) proline accumulation in roots preceded root growth reduction caused by $\mathrm{NaCl}$, (b) proline level in roots is inversely associated with root growth and (c) $\mathrm{NaCl}$-induced root growth reduction is produced in rice seedlings fed with Lproline or gabaculine which was found to result in a proline accumulation. When rice seedlings pretreated with $\mathrm{NaCl}$ or gabaculine were transferred to distilled water, root growth resumed and proline level in roots declined. These results suggest that growth inhibition of roots induced by $\mathrm{NaCl}$ is not irreversible and further support the close link between proline accumulation and root growth reduction induced by $\mathrm{NaCl}$. Proline accumulation induced by $\mathrm{NaCl}$ or $\mathrm{Na}_{2} \mathrm{SO}_{4}$ has also been demonstrated to be correlated with growth inhibition of callus [7,8].

Le Dily et al. [19] reported that the polyamine level of a habituated callus of Beta vulgaris was strongly diminished after treatment with gabaculine. It has been shown that exogenous application of polyamine can overcome the harmful effects of $\mathrm{NaCl}$ [20-22] and endogenous levels of polyamines decreased under $\mathrm{NaCl}$ stress [23]. However, our recent work provided evidence to show that endogenous polyamines do not play a significant role in the control of $\mathrm{NaCl}$-inhibited growth of rice seedlings [24]. Thus, the inhibition effect of gabaculine on root growth of rice seedlings is unlikely to be due to the decrease of polyamine levels.

Two pathways of proline biosynthesis, glutamate and ornithine pathways, have been reported [25]. In higher plants, the proline biosynthesis 
route is generally thought to involve the glutamate pathway which implies pyrroline 5-carboxylate synthase and pyrroline 5-carboxylate reductase [25]. In a few studies with germinated seedlings, a pathway using ornithine as the proline precursor has been put forward, in which ornithine aminotransferase is the key enzyme [25]. We do not know whether these two pathways contribute to the accumulation of proline in $\mathrm{NaCl}$-treated roots. Further studies should provide valuable information on the mechanism of proline accumulation in rice roots in response to $\mathrm{NaCl}$. In animal systems, ornithine aminotransferase is a reversible enzyme. It has been proposed that ornithine aminotransferase, which transforms glutamate 5-semialdehyde and glutamate into ornithine and ketoglutarate, could link proline catabolism to the synthesis of ornithine [26]. Gabaculine has been shown to be a potent inhibitor of ornithine aminotransferase [27]. It appears that proline accumulation in gabaculine-treated rice roots is most likely due to the inhibition of proline catabolism.

Possible functional roles of proline under stress conditions, as noted by Aspinall and Paleg [1], may include (a) cytoplasmic osmoticum, (b) the hydration of polymers, and (c) serving as a nitrogen source compound during periods of inhibited growth. Since growth is generally considered to be an energy-requiring process, elevated proline levels caused by $\mathrm{NaCl}$ are most likely acting as a way to save energy by inhibiting root growth and as a readily utilizable source of energy and amino groups once $\mathrm{NaCl}$ is relieved.

\section{Acknowledgements}

This work was supported financially by the National Science Council of the Republic of China (NSC 84-2321-B-002-097) to C.H.K.

\section{References}

[1] D. Aspinall and L.G. Paleg, Proline accumulation: Physiological aspects, in: L.G. Paleg and D. Aspinall (Eds.), The Physiology and Biochemistry of Drought Resistance in Plants, Academic Press, Sydney, 1981, pp. 205-241.

[2] S.F. Chandler and T.A. Thorpe, Variation from plant tis- sue cultures: biotechnological application to improving salinity tolerance. Biotech. Adv., 4 (1986) 117-135.

[3] H. Greenway and R. Munns, Mechanism of salt tolerance in nonhalophytes. Annu. Rev. Plant Physiol., 31 (1980) 149-190.

[4] A.E. Moftah and B.E. Michel, The effect of sodium chloride on solute potential and proline accumulation in soybean leaves. Plant Physiol., 83 (1987) 238-240.

[5] A.D. Hanson, C.E. Nelsen and E.H. Everson, Evaluation of free proline accumulation as an index of drought resistance using two contrasting barley cultivars. Crop Sci., 17 (1977) 720-726.

[6] A.D. Hanson, C.E. Nelsen, A.R. Pederson and E.H. Everson, Capacity for proline accumulation during water stress in barley and its implication for breeding for drought resistance. Crop Sci., 19 (1979) 489-493.

[7] S.F. Chandler and T.A. Thorpe, Characterization of growth, water relations, and proline accumulation in sodium sulfate tolerant callus of Brassica napus L. cv. Westar (Canola). Plant Physiol., 84 (1987) 106-111.

[8] F. Perez-Alfocea, A. Santa-Cruz, G. Guerrier and M.C. Bolarin, $\mathrm{NaCl}$ stress-induced organic solute changes on levels and calli of Lycopersicon esculentum, L. Pennellii and their interspecific hybrid. J. Plant Physiol., 143 (1994) 106-111.

[9] L.S. Bates, R.P. Waldren and I.D. Teare, Rapid determination of free proline for water-stress studies. Plant Soil, 39 (1973) 205-207.

[10] C.C. Lin and C.H. Kao, $\mathrm{NaCl}$ stress in rice seedlings: effect of exogenous polyamine on seedling growth. Chinese Agron. J., 4 (1994) 167-171.

[11] T.J. Flowers and A.R. Yeo, Variability in the resistance of sodium chloride salinity within rice (Oryza sativa $\mathbf{L}$.) varieties. New Phytol., 88 (1981) 363-373.

[12] C.C. Lin and C.H. Kao, $\mathrm{NaCl}$ stress in rice seedlings: effects of L-proline, glycinebetaine, L- and D-asparagine on seedling growth. Biol. Plant, 37 (1995) 305-308.

[13] R.P. Kandpal and N.A. Rao, Water stress induced alternations in the properties of ornithine aminotransferase from ragi (Eleusine coracana) leaves. Biochem. Int., 5 (1982) 297-302.

[14] F. Hervieu, F. Le Dily, J. Le Saos, J.-P. Billard and C. Huault, Inhibition of plant ornithine aminotransferase by gabaculine and 4-amino-5-hexynoic acid. Phytochemistry, 34 (1993) 1231-1234.

[15] F. Le Dily, J.-P. Billard, F. Le Saos and C. Huault, Effects of $\mathrm{NaCl}$ and gabaculine on chlorophyll and proline levels during growth of radish cotyledons. Plant Physiol. Biochem., 31 (1993) 303-310.

[16] R.A. Yeo and J.T. Flowers, Accumulation and localization of $\mathrm{Na}^{+}$within the shoots of rice (Oryza sativa L.) varieties differing in salinity resistance. Physiol. Plant., 56 (1982) 343-348.

[17] R. Krishnamurthy, M. Anbazhagan and A.K. Bhagwat, Accumulation of free amino acids and distribution of $\mathrm{Na}^{+}, \mathrm{Cl}^{-}$and $\mathrm{K}^{+}$in rice varieties exposed to $\mathrm{NaCl}$ stress. Indian J. Plant Physiol., 30 (1987) 183-188. 
[18] D. Roy, A. Bhunia, N. Basu and S.K. Banerjee, Effect of $\mathrm{NaCl}$-salinity on metabolism of proline in salt-sensitive and salt-resistant cultivars of rice. Biol. Plant., 34 (1992) 159-162.

[19] F. Le Dily, C. Huault, Th. Gaspar and J.-P. Billard, Gabaculine as a tool to investigate the polyamine biosynthesis pathway in habituated callus of Beta vulgaris (L.). Plant Growth Regul., 13 (1993) 221-223.

[20] R. Krishnamurthy, Amelioration of salinity effect in sait tolerant rice (Oryza sativa L.) by foliar application of putrescine. Plant Cell Physiol., 32 (1991) 699-703.

[21] L. Prakash and G. Prathapasenan, Effect of $\mathrm{NaCl}$ salinity and putrescine on shoot growth, tissue ion concentration and yield of rice (Oryza sativa L. GR3). J. Agric. Crop Sci., 160 (1988) 325-334.

[22] L. Prakash and G. Prathapasenan, Putrescine reduces $\mathrm{NaCl}$-induced inhibition of germination and early seedling growth of rice (Oryza sativa L.). Aust. J. Plant Physiol., 15 (1988) 761-767.
[23] L. Prakash, $\mathrm{M}$. Dutt and G. Prathapasenan, $\mathrm{NaCl}$ alters contents of nucleic acids, protein, polyamines and the activity of agmatine deiminase during germination and seedling growth of rice (Oryza sativa L.). Aust. J. Plant Physiol., 15 (1988) 769-776.

[24] C.C. Lin and C.H. Kao, Levels of endogenous polyamines and $\mathrm{NaCl}$-inhibited growth of rice seedlings. Plant Growth Regul., 17 (1995) 15-20.

[25] F. Hervieu, F. Le Dily, C. Huault and J.-P. Billard, Contribution of ornithine aminotransferase to proline accumulation in $\mathrm{NaCl}-$ treated radish cotyledons. Plant $\mathrm{Cel}$ Environ., 18 (1995) 205-210.

[26] M.E. Jones, Conversion of glutamate to ornithine and proline: pyrroline-5-carboxylate, a possible modulator of arginine requirements. J. Nutr., 115 (1985) 509-515.

[27] J.M. Jung and N. Seiler, Enzyme-activated irreversible inhibitors of L-ornithine: 2-oxoacid aminotransferase. J. Biol. Chern., 253 (1978) 7431-7439. 